Supplement of Nonlin. Processes Geophys., 23, 205-213, 2016

http://www.nonlin-processes-geophys.net/23/205/2016/

doi:10.5194/npg-23-205-2016-supplement

(C) Author(s) 2016. CC Attribution 3.0 License.

(c) (1)

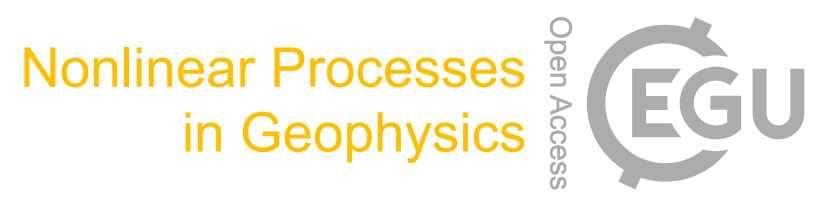

Supplement of

\title{
Multifractal behaviour of the soil water content of a vineyard in northwest Spain during two growing seasons
}

José Manuel Mirás-Avalos et al.

Correspondence to: José Manuel Mirás-Avalos (jose.manuel.miras.avalos@xunta.es)

The copyright of individual parts of the supplement might differ from the CC-BY 3.0 licence. 
Multifractal behaviour of the soil water content of a vineyard in NW Spain during two growing seasons. Mirás-Avalos et al. (Supplementary Materials)

\section{Supplementary information}

Table S1. Summary of climate variables (temperature, rainfall, $\mathrm{ET}_{0}$ and $\mathrm{ET}_{\mathrm{c}}$ ), irrigation water applied and harvest date for the studied and irrigation periods in 2011 and 2012.

\begin{tabular}{|c|c|c|c|}
\hline & & 2011 & 2012 \\
\hline Measurement period & & 14 June to 26 August & 14 June to 26 August \\
\hline \multirow[t]{3}{*}{ Temperature $\left({ }^{\circ} \mathrm{C}\right)$} & Maximum & 28.86 & 28.21 \\
\hline & Minimum & 12.44 & 12.33 \\
\hline & Mean & 20.15 & 19.67 \\
\hline Rainfall (mm) & & 25.60 & 65.60 \\
\hline $\mathrm{ET}_{0}$ & & 230.78 & 344.91 \\
\hline $\mathrm{ET}_{\mathrm{c}}$ & & 184.63 & 275.93 \\
\hline Irrigation period & & 9 July to 16 August & 20 July to 22 August \\
\hline \multirow[t]{3}{*}{ Temperature $\left({ }^{\circ} \mathrm{C}\right)$} & Maximum & 29.14 & 30.37 \\
\hline & Minimum & 12.61 & 12.77 \\
\hline & Mean & 20.36 & 20.82 \\
\hline Rainfall (mm) & & 10.20 & 29.20 \\
\hline $\mathrm{ET}_{0}$ & & 117.86 & 162.52 \\
\hline $\mathrm{ET}_{\mathrm{c}}$ & & 94.28 & 130.02 \\
\hline Irrigation (mm) & & 39.67 & 50.00 \\
\hline Harvest date & & $14^{\text {th }}$ September & $13^{\text {th }}$ September \\
\hline
\end{tabular}


Figure S1. Selected plots of the natural logarithms of the partition function, $\chi(q, \delta)$, versus the time resolution, $\delta$ : a) rain-fed treatment at $20 \mathrm{~cm}$ depth in 2011; b) irrigated treatment at $20 \mathrm{~cm}$ depth in 2011.

a)
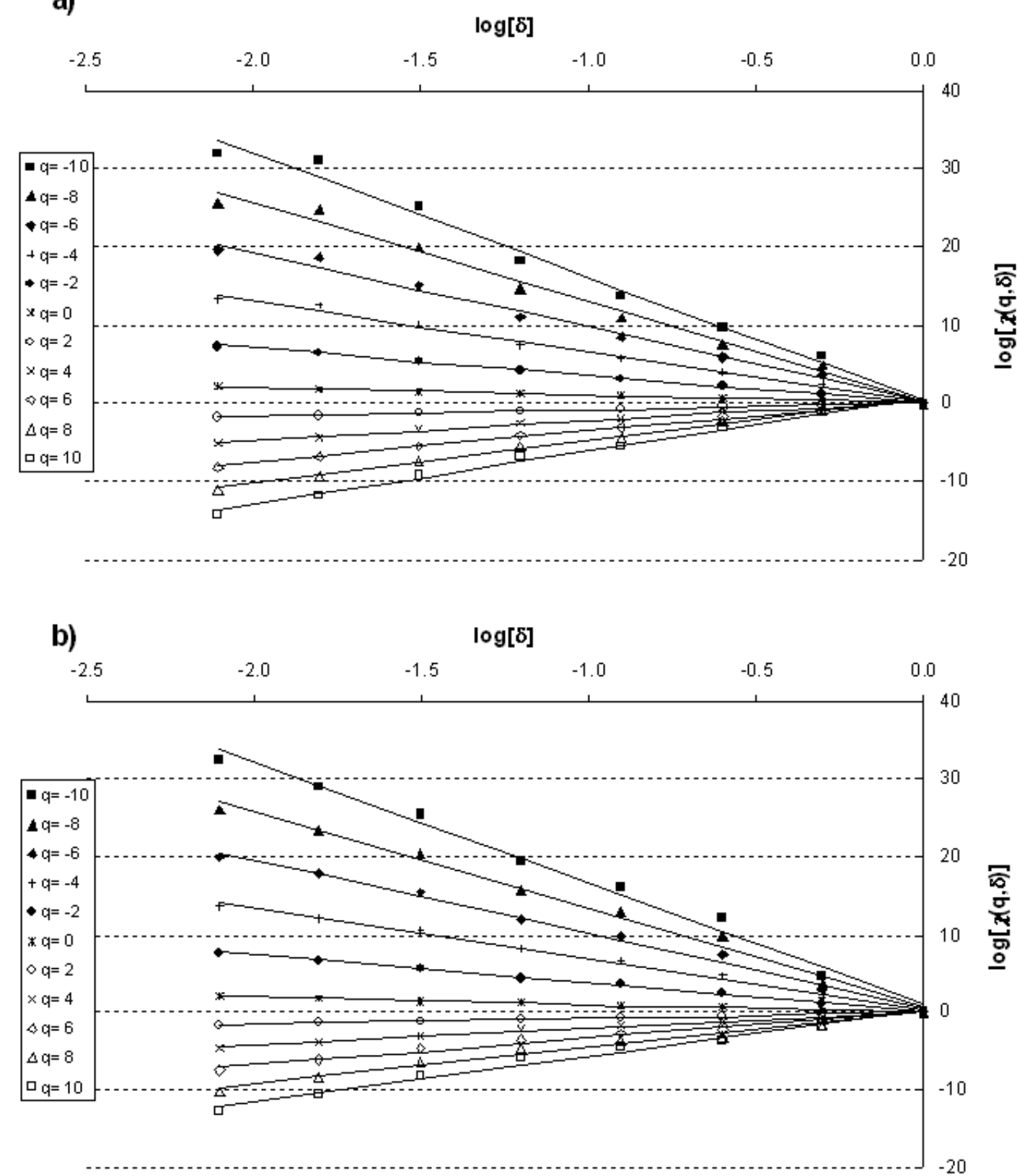
Figure S2. Mass exponents, $\tau(q)$, of soil water content averaged from 20 to $60 \mathrm{~cm}$ depth for rain-fed and irrigation treatments in 2011 and 2012.
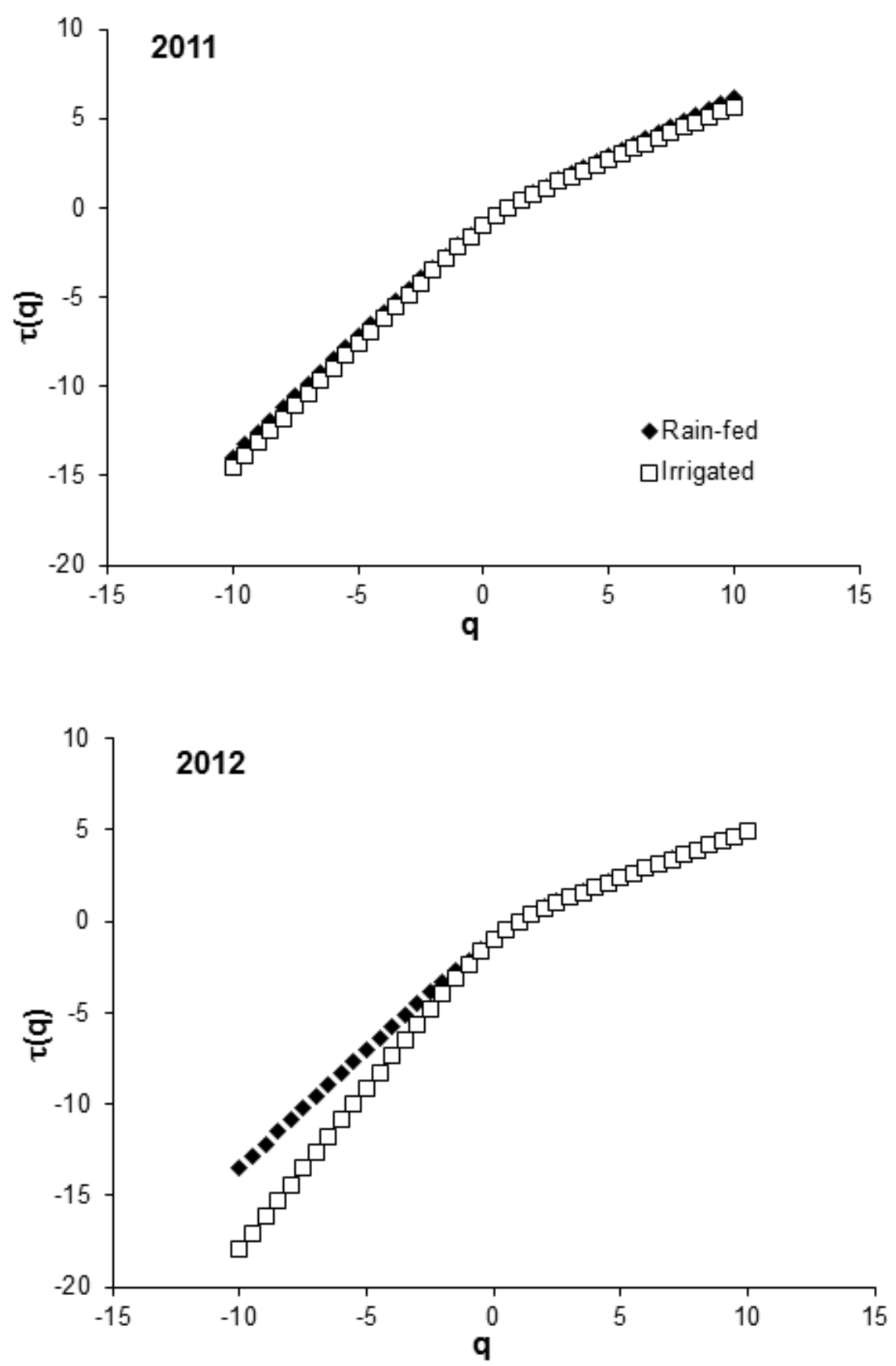